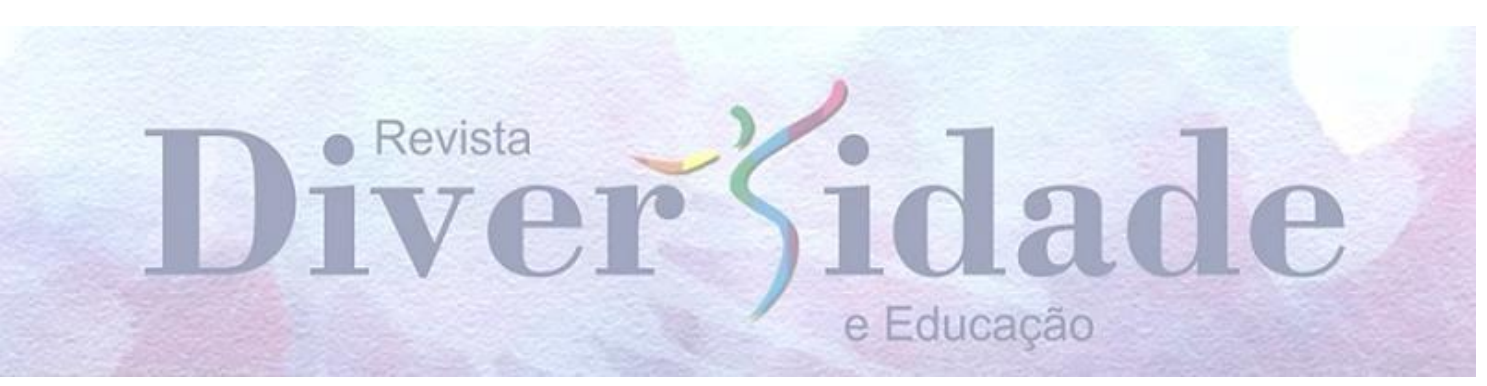

\title{
GÊNERO E SEXUALIDADE NA EDUCAÇÃO BRASILEIRA EM TEMPOS DE MOVIMENTO ESCOLA SEM PARTIDO
}

\author{
GÉNERO Y SEXUALIDAD EN LA EDUCACIÓN BRASILEÑA EN \\ TIEMPOS DE MOVIMIENTO ESCUELA SIN PARTIDO
}

\section{GENDER AND SEXUALITYIN BRAZILIAN EDUCATION IN TIMES OF NON PARTISAN SCHOOL MOVEMENT}

\author{
Ramon Roberto de Jesus Barroso1 \\ Lana Claudia Macedo da Silva 2
}

\section{RESUMO}

O foco desta pesquisa é discutir como movimentos ultraconservadores, especialmente o Movimento Escola Sem Partido tem se organizado para a retirada de estudos e reflexões sobre gênero e sexualidade das escolas brasileiras. Com base na abordagem qualitativa da pesquisa, realizamos estudos teóricos e documentais, referenciados em autoras como: Scott (1995), Louro (2007) (2019), Paraiso (2016), Mattos (2018), e nos autores: Penna (2016a) (2016b), Seffner (2016) e Miguel (2017). Concluiu-se que movimentos ultraconservadores tem se utilizado de um certo pânico moral para subverter conceitos científicos atribuídos a gênero e sexualidade, propagando discursos conservadores nos meios sociais, criando uma cortina de fumaça, resultando na falácia chamada "ideologia de gênero". Tal discurso tem sido utilizado como estratégia do MESP para impedir que o tema seja trabalhado e re-inserido em documentos educacionais como o Plano Nacional de Educação - PNE (2014-2024) e nas proposições de currículos escolares oficiais - Base Nacional Comum Curricular (BNCC).

PALAVRAS-CHAVE: Movimentos ultraconservadores. Gênero. Sexualidade. Escola.

\section{RESUMEN}

El enfoque de esta investigación es discutir cómo movimientos ultraconservadores, especialmente el Movimiento Escuela Sin Partido (MESP) tiene se organizado para la retirada de estudios y reflexiones sobre género y sexualidad de las escuelas brasileñas. Con base en el abordaje cualitativo de la investigación, realizamos estudios teóricos y documentales, basados en autoras como: Scott (1995), Louro (2007) (2019), Paraiso (2016), Mattos (2018), y en los autores: Penna (2016a) (2016b), Seffner (2016) y Miguel 
(2017). Se concluyó que movimientos ultraconservadores se habían utilizado de cierto pánico moral para subvertir conceptos científicos atribuidos a género y sexualidad, propagando discursos conservadores en los medios sociales, creando una cortina de humo, resultando en la falacia llamada "ideología de género". Ese discurso ha sido utilizado como estrategia del MESP para impedir que el tema sea trabajado y re-inserido en documentos educacionales como el Plan Nacional de Educación - PNE (2014-2024) y en las proposiciones de currículos escolares oficiales - Base Nacional Común Curricular (BNCC).

PALABRAS-CLAVE: Movimientos ultraconservadores. Género. Sexualidad. Escuela.

\section{ABSTRACT}

The focus of this research is to discuss how the ultraconservative movements, especially the Non Partisan School Movement, have caused the removal of the studies and questions about gender and sexuality in the brazilian educational curriculum. Based on the qualitative research approach, we did theoretical and documentary studies, referenced in female authors as: Scott (1995), Louro (2007) (2019), Paraiso (2016), Mattos (2018), and in male authors as: Penna (2016a) (2016b), Seffner (2016) e Miguel (2017). It was concluded that ultraconservative movements have taken advantage of the moral panic to subvert the scientific concepts assigned to gender and sexuality, disseminating conservative discourse in social environment, creating a smoke screen that results in the fallacy called "Queer Theory". That's peech has been utilized as a strategy of MESP to stop the theme from being worked andreinserted in educational files like the National Education Plan (2014-2024) and in the prepositions of the new educational resumes that have as reference, the National Curricular Common Base (BNCC). KEYWORDS: Ultraconservative movements. Gender. Sexuality. School.

$$
* * *
$$

As campanhas antigênero também podem ser entendidas como um projeto de produção alternativa de conhecimento, voltado a desconstruir as perspectivas pós-estruturalistas no campo das ciências sociais e das humanidades. Essas vertentes teóricas são descritas como sendo ideológicas e desconectadas dos achados inquestionáveis das ciências naturais, particularmente os estudos biológicos, médicos e psicológicos alinhados com concepções essencialistas sobre as diferenças sexuais entre homens e mulheres (incluindo as diferenças entre os cérebros dos homens e das mulheres) e a complementaridade dos sexos masculinose

femininos.

David Paternotte e Roman Kuhar

\section{Introdução}

O presente estudo é resultado de uma pesquisa de Conclusão de Curso realizada para a obtenção do Grau de Licenciado Pleno em Pedagogia pela Universidade do Estado do Pará - UEPA, no qual tratou-se do tema, gênero e sexualidade na escola: entre discursos ultraconservadores e práticas de resistência. Nessa perspectiva, objetiva-se 
compartilhar parcialmente os resultados da pesquisa como forma de contribuição com o tema em voga, apresentando novas reflexões sobre este, sem a pretensão de esgotar tal discussão.

As motivações para realização dessa pesquisa, foram as participações nos espaços acadêmicos como congressos, encontros, seminários etc, onde constantemente observamos discussões acerca da organização de movimentos ultraconservadores, muitos deles de base cristã para a retirada das discussões sobre Gênero e Sexualidade da Educação Básica brasileira.

Ao observar o meio social e pesquisar de forma aprofundada sobre o tema, verificamos muitas movimentações de grupos conservadores em relação à retirada do gênero e sexualidade do currículo escolar. Destacam-se, sobretudo, a proposição de Projetos de Lei em vários municípios e estados brasileiros, também em nível federal, que visam à alteração da legislação educacional para a proibição da temática dentro das escolas, estando reunidos sob a chamada Escola Sem Partido.

Um outro fato marcante nessa década que levou à realização da pesquisa, foi o debate em torno do Plano Nacional de Educação- PNE, para retirada ou inserção dos debates em torno do campo de gênero e sexualidade das estratégias e metas desse documento, e mais recentemente as disputas travadas em relação a esse tema na elaboração da Base Nacional Comum Curricular-BNCC.

A partir de tais observações, vivências e reflexões, definimos a pergunta de pesquisa, buscando discutir como os movimentos ultraconservadores reunidos sob a Escola Sem partido tem se organizado para a retirada das questões de gênero e sexualidade do campo educacional brasileiro.

Na pesquisa adotamos a definição de Scott (1995, p. 21), que nos diz que o conceito de gênero se relaciona a "um elemento constitutivo de relações sociais baseado nas diferenças percebidas entre os sexos". Gênero, portanto, compreende construções sociais a respeito de papeis atribuídos para homens e mulheres, entendendo suas origens históricas e relacionados com os símbolos culturais, as normas estabelecidas pela sociedade, as noções de fixidez e de identidades subjetivas; apontando também o gênero primariamente como uma forma de significar as relações de poder.

O conceito de sexualidade adotado nessa pesquisa baseia-se em Louro (2007), pontuando que esse termo se refere ao modo afetivo como um sujeito se relaciona com o outro, esse podendo viver sua sexualidade com parceiros do mesmo sexo, do sexo oposto, 
de ambos os sexos ou sem parceiro. Para além dessa definição, considera-se o modo como estabelecemos nossas relações interpessoais, a forma de significação dos sentimentos e comportamentos de cada ser humano, levando em conta construções sociais e culturais estabelecidas em cada época.

Atualmente, movimentos ultraconservadores vêm deturpando e distorcendo esses conceitos, rotulando-os de ideologia de gênero, enevoando uma visão para se pensar que a escola estaria promovendo um processo ideológico com os estudantes, principalmente com a conquista de espaços no currículo escolar por grupos considerados minorias sociais como os LGBT+ 3.

Nesse sentido, o objetivo da pesquisa foi discutir de que forma Movimentos ultraconservadores, especialmente o Escola Sem Partido tem se organizando para a retirada de estudos e reflexões sobre gênero e sexualidade das escolas brasileiras. visando apresentar um breve levantamento sobre esse tema na sociedade, do período de 1990 ao momento atual, refletir sobre a chamada ideologia de gênero, slogan propagado pelos movimentos ultraconservadores em relação a temática e, ainda, descrever como gênero e sexualidade vem sendo suprimidos de algumas legislações educacionais como o Plano Nacional de Educação (PNE) e a Base Nacional Comum Curricular (BNCC), nos últimos anos.

A justificativa, para realização da pesquisa, se fortalece ao observar que essa discussão é um tanto quanto nova no âmbito das instituições de pesquisa, precisando haver maior e mais socializada produção científica que contribuam com o tema, refletindo sua importância no meio educacional, possibilitando às professoras e professores que englobem as discussões de gênero e sexualidade como forma de combate ao preconceito e discriminação decorrente das identidades de gênero e sexualidade, visto que ainda são muitas e muitos que sofrem com esse tipo de violência no meio escolar.

A Metodologia utilizada foi de abordagem qualitativa com base em Minayo (2002), pontuando que nessa abordagem considera-se um universo de significados, motivos, aspirações, crenças, valores e atitudes, o que corresponde a um espaço mais profundo das relações, dos processos e dos fenômenos que não podem ser reduzidos à operacionalização de variáveis. Os dados produzidos ao longo da pesquisa não se

3 Lésbicas, Gays, Bissexuais, Travestis e Transgêneros e demais identidades e orientações sexuais. 
reduzem ao rol de informações isoladas, elas estão imersas em um universo de significados (CHIZZOTI, 2001).

Destarte, realizamos uma pesquisa teórica "aquela que se realiza a partir do registo de pesquisas anteriores, em documentos impressos, como livros, artigos, teses e etc..." (SEVERINO, 2007, p. 122), visando uma revisão da literatura acerca do tema pesquisado, e uma pesquisa documental, aquela que utiliza materiais que ainda não receberam um tratamento analítico, tais como jornais, fotos, filmes, gravações, documentos legais (SEVERINO, 2007). Nesse caso, os materiais de nossas análises foram os PLs inspirados na ESP e os documentos educacionais: Plano Nacional de Educação (PNE) e Base Nacional Comum Curricular (BNCC).

O texto está organizado em três (3) seções: Movimento Escola Sem Partido e o momento atual do discurso sobre gênero e sexualidade, ideologia de Gênero, o que é isso?, o silenciamento do gênero e da sexualidade no PNE e na BNCC, por fim, tecemos as considerações finais.

\section{Movimento Escola Sem Partido e o momento atual do discurso sobre gênero e sexualidade}

Nos últimos anos destaca-se uma distorção sobre os conhecimentos produzidos em relação a gênero e sexualidade, onde atualmente "empreendedores morais" têm atacado diariamente esses estudos que levaram anos para serem construídos e solidificados. Nessa perspectiva, propagam uma rotulação a gênero e sexualidade, sob uma denominada ótica de "ideologia de gênero".

As primeiras manifestações voltadas para o slogan chamado de "ideologia de gênero" do qual se tem referência, constam a partir da década de 1990, em que, nas concepções de Balieiro (2018) e Miskolci (2018), surgem movimentações em contraposição às discussões de gênero, sobretudo alavancados pela Igreja católica.

Situando-se historicamente nesse período da década de 1990, Balieiro (2018) e Mikoslci (2018), destacam a Conferência do Cairo sobre População e Desenvolvimento, de 1994 e a Conferência Mundial das Mulheres de Pequim, ocorrida em 1995, ambas marcadas pela inclusão das discussões sobre gênero e sexualidade na pauta dos Direitos Humanos internacionalmente. Dessa forma, Miskolci (2018), pontua que nesse período se forja "uma reação contra o uso do conceito de gênero em acordos internacionais sobre direitos humanos" (p. 3-4). 
A inclusão crescente de pautas voltadas para o gênero e a sexualidade em assuntos políticos, educacionais, sobre direitos humanos, entre outros, se torna preocupante para setores da igreja católica, percebendo que cada vez mais seus fiéis ganhavam autonomia de pensamento, independência da hierarquia cristã e posicionamentos particulares em relação a essas discussões. Assim, consideraram que precisava criar um mecanismo para barrar esses avanços, por meio da esfera moral, onde as instituições católicas possuem maior autoridade.

Nesse período, a partir da inserção contínua desses debates sobre gênero, principalmente na agenda da ONU, a igreja católica inicia o enfrentamento a esse tema, entendendo que essas discussões seriam um mecanismo para atacar e desestabilizar o modelo de família patriarcal e, ao mesmo tempo, como forma de combate ao aborto e a homossexualidade, como revelam Paternotte e Kuhar (2018), ao expressarem que:

O Vaticano temia que os direitos sexuais e reprodutivos se tornassem um veículo para o reconhecimento internacional do aborto, ataques à maternidade tradicional e uma legitimação da homossexualidade. Frente à recém-reconhecida noção de gênero, privilegiou a ideia de "complementaridade entre os sexos" e promoveu a noção de "igual dignidade" em oposição a de "igualdade de direitos". Nesse contexto, o gênero - que passou a fazer parte do discurso da ONU naquele momento - foi interpretado pela Santa Sé como um meio estratégico de atacar e desestabilizar a família natural (PATERNOTTE; KUHAR, 2018, p. 511).

A partir das leituras de Cara (2016), Miguel (2016) e Penna (2016b), verifica-se que esses primeiros discursos se iniciam em Roma, no pontificado do Papa Wojtyla (João Paulo II) que durou mais de duas décadas e perpassou a segunda e terceira onda feminista, como são difundidas as ações desse movimento, tendo a colaboração do cardeal Ratzinger, que sucedeu o papado de João Paulo II, no ano de 2005. Na década de 2000, delineou-se o adversário a ser combatido, a "ideologia de gênero"4, assim, chamada no Brasil, e possuindo outras denominações mundo afora.

${ }_{4}$ Cabe observar que, antes que eclodissem as polêmicas e os enfrentamentos que aqui se procura problematizar, o conceito sociológico "ideologia de gênero" já tinha sido elaborado, com o intuito de permitir identificar, compreender e criticar os processos de naturalização das relações de gênero, a subordinação das mulheres, a assimetria de poder e de acesso aos recursos por parte das mulheres em relação aos homens. De acordo com tal entendimento, são manifestações de ideologias de gênero o machismo, o sexismo, a misoginia, a homofobia, assim como esta polêmica empreendida pelo Vaticano contra o "gender" e a "teoria/ideologia do gender" (JUNQUEIRA, 2017, p. 27). 
O pontificado de Wojtyla foi marcado pelo combate à posição política do movimento feminista, no que tange à sexualidade e gênero. Por meio de vários textos o pontífice deixou claro seu posicionamento, defendendo que a busca pela equidade de gênero rebaixaria as mulheres, deixando de lado sua identidade "feminina" dotada por Deus (MIGUEL, 2016, p. 598).

Nessa perspectiva, o questionamento sobre os papéis sociais exercidos por homens e mulheres, se contrapõe à construções sociais criadas e impostas sobre os corpos masculinos e femininos, além de questionar a heteronormatividade e os arranjos familiares tradicionais. Na concepção dos defensores da "ideologia de gênero", esses questionamentos causam uma confusão mental e desordem social, que precisa ser combatida.

No entanto, o posicionamento contrário de Papa João Paulo II aos conceitos de gênero adotados cientificamente, se reafirma após sua morte, nos papados seguintes, até a atualidades sob o comando de Papa Francisco, apoiado por diversas documentos publicados pela Santa Sé e nos discursos de Arcebispos, autoridades e congregações católicas. Nesse sentido,

A "ideologia de gênero" não deve, contudo, ser entendida como uma mera tentativa de colocar em movimento a teologia de João Paulo II ou uma nova versão de tropos mais antigos. Iniciada sob o papa polonês, esta estratégia foi reafirmada pelos papas Bento XVI e Francisco, com o apoio de várias congregações e dicastérios romanos, em particular a Congregação para a Doutrina da Fé, o Pontifício Conselho para a Família, o Pontifício Conselho para a Leigos, o Pontifício Conselho para a Cultura e a Pontifícia Academia para a Vida. Esses esforços levaram, em 2003, à publicação do Lexicon: termos ambíguos e discutidos sobre a vida familiar e questões éticas pelo Pontifício Conselho para a Família, com o apoio da Congregação para a Doutrina da Fé (PATERNOTTE; KUHAR, 2018, p. 512).

É nessa perspectiva que Junqueira (2017) destaca a mobilização mundial da Igreja católica para o combate às discussões sobre gênero, havendo ações para reafirmação dos valores tradicionais/morais da doutrina católica, em muitos países de diversos continentes. Para esse autor:

Nos últimos anos, em dezenas de países de todos os continentes, presencia-se a eclosão de um ativismo religioso reacionário que encontrou no "gênero" o principal mote em suas mobilizações. "Gênero", "ideologia de gênero", "teoria do gênero" ou expressões afins são brandidos em tons alarmistas, conclamando a sociedade para 
enfrentar um inimigo imaginário comum. E, em nome da luta contra ele, se empreendem ações políticas voltadas a reafirmar e impor valores morais tradicionais e pontos doutrinais cristãos dogmáticos e intransigentes (JUNQUEIRA, 2017, p. 25-26).

Nesse sentido, a igreja passa a subverter os significados atribuídos ao gênero e a sexualidade, criando ideias alternativas para contestar os conhecimentos até então produzidos sobre o tema, criando, desse modo, desentendimentos no senso comum, para que as pessoas acreditem e propagem a visão religiosa sobre o assunto. Dessa maneira,

\begin{abstract}
A Igreja passou a propagar ideias alternativas usando e subvertendo as noções que repudia e, também, contestar a suposta hegemonia cultural e política do "gênero pós moderno" no contexto de uma batalha global das idéias. A Igreja, portanto, utiliza noções progressistas como "gênero" ou "feminismo" alterando seu significado, criando confusão no entendimento das pessoas comuns e ressignificando a pauta que vozes liberais vinham tentando articular nas últimas décadas (PATERNOTTE; KUHAR, 2018, p. 512).
\end{abstract}

Para Paternotte e Kuhar (2018) a igreja católica desempenhou um papel fundamental para o crescimento e propagação sobre a chamada ideologia de gênero. Em muitas situações ofereceu meios para que ativistas e intelectuais se reunissem para discutir suas visões e estratégias em prol daquilo que muitos líderes da igreja consideravam uma prioridade política, ressaltando que a instituição:

Também forneceu sua poderosa rede de mobilização e difusão. No entanto, embora o modo de produção desse discurso seja relativamente bem conhecido, sua difusão no mundo católico e as formas como ele alimenta as mobilizações locais exigem mais investigação. É preciso, de fato, compreender os canais por meio dos quais essa estratégia é propagada, inclusive para além dos círculos católicos, bem como as maneiras pelas quais sofre adaptações ao ser adotada em um contexto específico (PATERNOTTE; KUHAR, 2018, p. 513).

Partindo desses pressupostos e voltando-se para a construção e difusão do discurso ultraconservador sobre gênero e sexualidade no cenário brasileiro, destaca-se a segunda década dos anos 2000. Nesse período, tomando como base o pensamento de Vencato et al. (2018), a igreja católica alavancou as discussões sobre gênero e sexualidade no Brasil, sob a lógica da ideologia de gênero, se articulando com as igrejas evangélicas e juntas pressionando o legislativo. 
Ressaltando esse primeiro momento na década dos anos 2000 e reafirmando o papel de grupos conservadores, muitos deles de base cristã, como agentes de promoção dos discursos de ataque ao gênero e sexualidade e aos direitos sociais de grupos historicamente marginalizados e voltando-se ao campo educacional, Mattos (2018) enfatiza que:

No cenário político brasileiro da segunda década dos anos 2000, o combate à "ideologia de gênero" foi encampado por grupos ultraconservadores, muitos deles de base religiosa cristã, que têm promovido ataques aos direitos sexuais e reprodutivos de mulheres, da população LGBT, e às políticas públicas voltadas para esses grupos. No campo da educação, esses ataques concretizaram-se em projetos de lei apresentados pelo ESP nos âmbitos federal, estaduais e municipais (MATTOS, 2018, p. 576).

No entanto, como destacado por Mattos (2018) e Vencato et al. (2018), no caso brasileiro o termo "ideologia de gênero" tem se concretizado com as movimentações nos poderes legislativos, sob as proposições da "Escola Sem Partido" que tem se utilizado desse slogan. Portanto, é necessário destacar como esse movimento surge no Brasil e como suas ideias se propagam nos discursos conservadores e em forma de Projetos de lei. Nessa perspectiva, a primeira proposição da Escola Sem Partido cabe ao jurista Miguel

Nagib, no ano de 2004. Nessa primeira versão, o objetivo foi combater a chamada "doutrinação marxista" 5. No entanto, passaram-se alguns anos e o ESP ficou escondido, sem ganhar notoriedade. A partir de 2014, o projeto começa a ser abarcado pela ala da direita brasileira, por políticos e setores mais conservadores da sociedade, destacando-se as igrejas evangélicas neopentecostais. Assim, começam a ser apresentados projetos com esse teor na câmara de vereadores de vários municípios, assembleias legislativas e no congresso nacional (MIGUEL, 2016; PENNA, 2016b).

Entre um episódio e outro, no ano de 2011, um fato marcante de distorção sobre as noções cientificas de gênero e sexualidade que merece destaque, foi a discussão sobre o chamado "kit gay". Trata-se de material didático que visa o combate à violência e à descriminação às pessoas LGBT+ nas escolas brasileiras, que começava a ser distribuído pelo Ministério da Educação -MEC naquele período.

${ }_{5}$ No Brasil, hoje, as noções transmitidas de política e cidadania estão flagrantemente contaminadas de conceitos marxistas, particularmente no ensino de nível médio. O que se ensina nas aulas de História, Sociologia, Geografia, e mesmo em Literatura ou Filosofia, não passa de doutrinação. Disponível em: <http://escolasempartido.org/artigos/173-a-doutrinacao-ideologica-nas-escolas>. 
A repercussão sobre esse material que fazia parte de um programa chamado de Escola sem Homofobia se deu de forma negativa, sobretudo, promovido pela bancada evangélica, que alavancou as discussões nos espaços midiáticos, até sua retirada de circulação no dia 26 de maio de 2011. Sobre esse episódio Balieiro (2018) destaca que:

\begin{abstract}
A oposição a tal agenda de direitos humanos se efetuou a partir de um recurso discursivo estratégico: uma mudança na chave interpretativa na qual a expansão de direitos à população LGBT contida nas iniciativas governamentais era concebida como uma ameaça às crianças. [...] $\mathrm{A}$ construção da ameaça às crianças revelou-se de intenso apelo à opinião pública, recebendo publicidade e tomando caráter passional, com consequências efetivas ao barrar iniciativas de combate à homofobia ou de respeito à diversidade sexual (BALIEIRO, 2018, s.p).
\end{abstract}

Destaca-se também, nesse período, a criação de projetos de lei nas assembleias legislativas de 7 (sete) estados brasileiros, além do Distrito Federal, que visam implementar a Escola Sem Partido, lei que proibiria discussões em torno de gênero e sexualidade, além de outros temas que permeiam o ambiente escolar. Alguns desses projetos foram aprovados em municípios brasileiros como em Santa Cruz do Monte Castelo- PR e Picuí-PB, além do Estado do Alagoas em 2016 (PENNA, 2016, p.44-45). Esse último foi julgado pelo STF e considerado inconstitucional.

Projetos de lei como o PL 867/20156 de autoria do deputado federal Izalci Lucas (PSDB/DF), tinham por objetivo inserir o Projeto Escola Sem Partido na Lei de Diretrizes e Bases da Educação Nacional (LDB/EN, Lei No9394/96). Miguel (2017), destaca que esse projeto de lei, é o de maior ataque à democracia, dentre todos.

\footnotetext{
Assim, a educação deve ser baseada na "neutralidade política" (art. $2^{\circ}$ ) e a escola não pode desenvolver nenhuma atividade que possa "estar em conflito com as convicções religiosas ou morais dos pais ou responsáveis pelos estudantes" (art. $\left.3^{\circ}\right)$ - embora as instituições confessionais privadas possam exercer seu proselitismo, desde que contem com a anuência da família (art. $\left.3^{\circ}, \S 1\right)$. O artigo $5^{\circ}$ prevê que serão afixados cartazes nas escolas para que os estudantes saibam que podem denunciar seus professores. O programa se aplica ao material didático e a todos os níveis de ensino, incluindo o superior. $\mathrm{O}$ arrazoado apresentado consiste, quase que exclusivamente, na reprodução da "robusta justificativa" do MESP (MIGUEL, 2017, p. 608).
}

6 Disponível : https://www.camara.gov.br/proposicoesWeb/prop_arvore_tramitacoes;jsessionid 
Outro projeto em tramitação no Congresso é o PL 1859/2015 também de autoria de Izalci Lucas (PSDB/DF) e outros parlamentares. O projeto determina que se inclua na LDB o seguinte dispositivo:

A educação não desenvolverá políticas de ensino, nem adotará currículo escolar, disciplinas obrigatórias, ou mesmo de forma complementar ou facultativa, que tendam a aplicar a ideologia de gênero, o termo 'gênero' ou 'orientação sexual7.

O PL 5487/2016, de autoria do deputado Victório Galli (PSC/MT), aborda que o MEC fica proibido de "orientar e distribuir livros às escolas públicas que versem sobre orientação e diversidade sexual das crianças e adolescentes"8. Essa justificativa se baseia no PNE, do qual essas discussões foram suprimidas. Pelo projeto afirma-se que essa retirada não está sendo cumprida.

De autoria de Rogério Marinho (PSDB/RN), o PL 1411/2015, tramita isoladamente no congresso. Nesse projeto tem-se por objetivo caracterizar o crime de "assédio ideológico" e prevê de três(3) meses a um ano de detenção ou multa e acréscimos, caso o "assédio" parta do professor. No PL fica definido o assédio ideológico como:

Toda prática que condicione o aluno a adotar determinado posicionamento político, partidário, ideológico ou qualquer tipo de constrangimento causado por outrem ao aluno por adotar

posicionamento diverso do seu, independente de quem seja o agente9.

No senado, um PL de mesma natureza também tramita, de autoria do ex-senador Magno Malta (PR/ES). No Projeto de Lei 193/2016, tem-se como objetivo incluir a ESP na Lei de Diretrizes e Bases, enfatizando que o Ministério e as Secretarias de Educação terão que disponibilizar serviço para o acolhimento de denúncias contra professores e escolas (artigo $8^{\circ}$ ). O texto da lei será afixado em todas as escolas (artigo $3^{\circ}$ ) (MIGUEL, 2017, p. 610).

No final do ano de 2018, outra tentativa de inserção da ESP na educação brasileira, por meio da LDB, ganhou repercussão, após inúmeras tentativas fracassadas de votação

7 Disponível em:<http://www.izalci.com.br/projetos/>.

${ }_{8}$ Disponível: $<$ https://www.camara.leg.br/proposicoesWeb/fichadetramitacao?idProposicao=2087086\&ord $=0>$

${ }_{9}$ Disponível em:<https://www.camara.leg.br/proposicoesWeb/fichadetramitacao?idProposicao=1229808 
na câmara dos deputados. Esse projeto de lei PL 7180/2014, proposto pelo deputado Erivelton Santana (PSC-BA), traz como objetivo alterar o Art. $3^{\circ}$ da Lei 9394/96, incluindo, entre os princípios do ensino, o respeito às convicções do aluno, de seus pais ou responsáveis, dando precedência aos valores de ordem familiar sobre a educação escolar nos aspectos relacionados à educação moral, sexual e religiosa10.

Em razão da falta de quórum e da resistência por parte de alguns deputados de esquerda e por muitas professoras e professores, o presidente da comissão especial, deputado Marcos Rogério (DEM-RO), decidiu, no dia 11 de dezembro de 2018, não mais convocar reuniões do colegiado, dessa forma adiando a votação para o ano de 2019.

Os apoiadores desse PL argumentam, baseados na ideia da doutrinação realizada pelo professor e pelos materiais didáticos, que, segundo eles são de cunho marxista e influenciam os jovens alunos, assim, como a chamada "ideologia de gênero" e o “marxismo cultural”, são influências dos docentes na vida social dos estudantes.

No ano de 2019, uma nova proposição da ESP foi protocolada na Câmara dos deputados, dessa vez de autoria da Deputada Bia Kicis (PSL/DF). No projeto 246/19, a deputada propõe que os alunos tenham direito de gravar as aulas, segundo ela para que os pais possam acompanhar os processos pedagógicos e avaliar a qualidade do ensino, além da proibição de movimentações partidárias de grêmios estudantis. A ideia do PL é abranger todas as políticas voltadas à educação (Planos, currículos, BNCC, entre outros).

Além de projetos em tramitação na câmara e em assembleias legislativas, Sevilla e Seffner (2017), destacam os recentes casos de perseguição a diversos professores, acusados de doutrinação, seja ela, política, ou por debaterem questões no campo de gênero e da sexualidade.

Nesse sentido, Cara (2016) reforça a ideia que o projeto Escola Sem Partido se fundamenta na acusação no qual o professor doutrina seus alunos a partir de seus posicionamentos políticos e ideológicos. Portanto, deve-se impor limites à sua prática, justificando a criação de tais PL. Segundo ele, a ideia é que os professores sejam vigiados e controlados no exercício da docência, por meio da limitação à liberdade de cátedra.

Diante do objetivo de cada PL, nota-se, a priori, a concepção limitada de educação, que entende a dinâmica escolar como responsável apenas pela instrução dos alunos e não 
como capaz de possibilitar o desenvolvimento do pensamento crítico e da preparação desses sujeitos para conviver na diferença - de gênero, étnicas, religiosas, dentre outras.

Pela ESP, se reafirma o essencialíssimo de uma sociedade estática e imutável, que compreende os sujeitos sociais apenas pelo seu caráter biológico, reafirmando um modelo social pautado no patriarcalismo, nos valores conservadores da família burguesa e em um modelo educacional tradicional que considera os alunos como meras tabulas rasas e instrumentos de dominação/reprodução de ideias.

\section{"Ideologia de Gênero", o que é isso?}

O slogan "ideologia de gênero" se opõe as teorias de gênero, que levaram anos para serem construídos cientificamente, como discutimos anteriormente. Os defensores desse rótulo contrariam o acúmulo teórico em torno da reflexão sobre lugares e papeis ocupados socialmente por homens e mulheres. Nesse sentido, utilizando autores como Chiaradia \& Nascimento (2016),Penna (2016), Paraiso (2016) e Mattos (2018) destacamos a construção desse termo em contrapartida aos estudos de gênero.

Nessa perspectiva, Miguel (2017), reafirmando a posição de outros autores como Cara (2016) e Penna (2016), aponta que nos últimos anos tem sido notável o aumento dos discursos conservadores em contraposição à defesa da igualdade de direitos, no cenário político-social brasileiro. Em consonância com esse autor, no campo educacional, ressalta-se que:

O campo educacional mais amplo tem sido palco de controvérsias entre grupos conservadores (em sua maioria formada por grupos religiosos) por um lado e estudiosos e militantes por outro. Projetos como o chamado Escola sem partido se alastraram pelo Brasil (SEVILLA; SEFFNER, 2017, p. 1).

Os movimentos conservadores tem conquistado cada vez mais adeptos e simpatizantes, sobretudo, com o apoio de alguns religiosos (protestantes e católicos), políticos de extrema direita e grupos anticomunismo, ganhando reforço com as discussões sobre a chamada "ideologia de gênero" e discursos em defesa da família patriarcal.

Nesse sentido, no campo educacional, esses movimentos conservadores ganham visibilidade e se fortalecem com o discurso da escola como uma instituição que doutrina seus alunos, tendo no professor sua figura central, a partir do momento em que ele 
verbaliza suas análises políticas sobre assuntos do cenário atual brasileiro. No texto a seguir enfatiza-se que:

A concepção do movimento se apoia na crítica a duas práticas que ele considera comuns nas escolas: a "doutrinação política e ideológica dos alunos por parte dos professores" e a "usurpação dos direitos dos pais na educação moral e religiosa de seus filhos" (CHIARADIA; NASCIMENTO, 2016, p. 109 apud El País, 2016).

Essas autoras ressaltam que, apoiados pelo movimento da ESP, os discursos ultraconservadores, apresentam dois exemplos de professores e professoras: primeiramente aquele sujeito marxista, consequentemente ateu, que expressa análises de conjuntura diante de alunos oriundos de famílias religiosas predominantemente cristãs; e um outro professor, que estimula os atos sexuais, e práticas como a masturbação e a pornografia, para que os alunos tenham uma vida sexual ativa, isso por meio das aulas de educação sexual.

Paraíso (2016) enfatiza que esses grupos conservadores se articulam de todas as maneiras para alcançar seus objetivos, apoiando mudanças e controle não só na prática do professor, como nas leis e documentos educacionais, propondo projetos para o controle do currículo, dos livros didáticos, entre outros. Essa autora ressalta que:

Para atingir seus objetivos, os grupos reacionários não se intimidam
com nada. Se alguém diz que a ideologia de gênero é contrária ao que
está no Plano Nacional de Educação (PNE), os grupos reacionários, que
desejam "tapar os vazamentos da diferença", propõem mudar o PNE.
Se alguém diz que a ideia é contrária ao que determina a Lei de
Diretrizes e Bases da Educação Nacional (LDB), representantes desses
grupos fazem Projetos de Lei para mudar a LDB. Se alguém diz que é
contrário ao que está nos Parâmetros Curriculares Nacionais (PCN),
elabora-se projeto de lei para mudar os PCN. Também não se intimidam
em ter que controlar os materiais didáticos e as avaliações e criminalizar
o/a docente. Têm sido elaborados vários Projetos de Lei para dar conta
disso tudo (PARAÍSO, 2016, p. 392).

Os discursos de apoiadores da ESP utilizam termos falaciosos como forma de ataque à prática docente, de maneira a confundir a opinião pública, na tentativa de enquadrar situações para provar que de fato a chamada "ideologia de gênero" e a 
"doutrinação ideológica" tem um teor de verdade e existência, como afirma Mattos (2018),

Ao empregarem uma expressão que absolutamente não é utilizada no diverso e heterogêneo campo dos estudos de gênero e sexualidades, tais movimentos agrupam, de maneira simplista e pejorativa, distintas abordagens, reflexões e propostas metodológicas, promovendo um epistemicídio de ideias e conceitos que vêm sendo debatidos e construídos há décadas por feministas e teóricas/os LGBT (MATTOS, 2018, p. 576).

Nesses discursos falaciosos, Penna (2016a) revela a utilização de procedimentos comumente empregados para atacar os professores. Nesse sentido,

\begin{abstract}
Destaco dois procedimentos discursivos intrinsecamente articulados e utilizados nesse ataque aos professores. Um primeiro procedimento é a utilização de termos que não possuem uma definição precisa, de maneira que uma ampla gama de casos possa ser enquadrada usando essas expressões. Cito, como exemplo, os termos: "doutrinação ideológica", "ideologia de gênero" e "marxismo cultural". Em todos os casos, termos cunhados para desqualificar uma prática deturpando a sua concepção original (PENNAa, 2016, p. 94).
\end{abstract}

Portanto, o termo "ideologia de gênero", no cerne dos estudos de gênero, não apresenta cunho científico, se caracterizando como um conceito criado por grupos conservadores que visam retroceder os debates sobre sexualidade e gênero no âmbito social e escolar, na tentativa de instalar o pânico moralıl, criando ailusão de que a presença de tais discussões influenciarão na sexualidade e identidade de gênero do indivíduo. Nas palavras de Penna:

\begin{abstract}
A imagem mais chocante de todas é a que tem relação com o termo "ideologia de gênero". Este termo foi criado por grupos que tentam desqualificar e, até mesmo, demonizar o trabalho com a questão de gênero nas salas de aula. A meta, em grande parte já alcançada, é criar um termo que remeta a medos difusos de que as crianças aprenderiam a ser gays e lésbicas em sala de aula e que os professores estariam tentando destruir a família tradicional (PENNAa, 2016, p. 99).
\end{abstract}

${ }_{11}$ Barreiro et al. (2016) tendo como base o pensamento de Stanley Cohen, pontua que o pânico moral se caracteriza pelo fato da existência de um problema que ameaça a ordem e os valores tradicionais de uma sociedade, se baseando na moral, no entanto, sem que haja de fato provas concretas de sua existência, porém que causa medo, aversão, repulsão pelos membros desta. Nesse sentido se instaura uma cruzada moral em diferentes espaços e instituições sociais, como as igrejas e a mídia, que promovem estereótipos sobre determinados grupos, figuras, pessoas e etc. 
Concordando com a afirmativa acima, Mattos (2018) destaca o pânico moral criado para o combate aos estudos de gênero, da luta pela igualdade de direitos entre homens e mulheres e para a população LGBT, ressaltando que "a simplificação do amplo debate sobre gênero e sexualidades sob o rótulo "ideologia de gênero" contribui, ainda, para promover o descrédito pela discussão crítica junto à sociedade" (MATTOS, 2018, p. 576). Nessa perspectiva,

É crucial sublinhar que "ideologia de gênero" não designa os estudos de gênero, mas sim um termo originalmente criado em contraposição aos direitos de igualdade e ao ativismo feminista e das pessoas LGBT, bem como aos estudos que desconstroem a base essencialista e naturalista das ordens de gênero e sexualidade (MATTOS, 2018, p. 577).

Paraíso (2016) em continuidade ao posicionamento de Penna (2016a) e Mattos (2018), descreve que até alguns anos atrás o slogan ideologia de gênero, era utilizado na surdina, e de alguns anos para cá, tornou-se usual para o combate às lutas por igualdade de direitos. Para ela,

O termo ideologia de gênero trata-se, claramente, de um rótulo dogmático que, se antes era enunciado meio na surdina, agora se torna premissa para um ódio declarado às lutas por igualdade de direitos entre homens e mulheres, às discussões críticas sobre gênero e sexualidade na escola e aos direitos de todas as pessoas que não identificam seus desejos com os desejos dos heterossexuais (PARAÍSO, 2016. p. 392).

Para Seffner (2016), diante dos discursos e documentos do Movimento Escola Sem Partido, a identidade de gênero é vista como uma invenção de professores e professoras progressistas e feministas, que apontam para o gênero como uma opção. Essa tal invenção se opõe aos elementos biologicamente tidos como naturais. Na visão desse autor,

A isso os atores sociais desse movimento opõem certa noção que deriva
as identidades ou preferências em gênero e sexualidade de elementos
tidos como naturais e visíveis: a configuração da genitália e outros
elementos corporais, a ação dos hormônios que dão vida a desejos
sexuais biologicamente explicados e, portanto, naturais, ao código
genético que ao fim e ao cabo ditaria a pertença sexual e de gênero de
cada um, não deixando margem a dúvidas. Qualquer desvio disso
deveria ser contido, corrigido por cirurgia ou tratamento psicológico ou 
com medicação, ou simplesmente tolhido, impedindo sua expressão pública [...] (SEFFNER, 2016, p. 8).

Nessa perspectiva, Mattos (2018) reafirma o posicionamento anterior, pontuando a ideia que paira sobre a "ideologia de gênero", prevalecendo-se da construção do pânico moral criado sobre os estudos de gênero e sexualidade, que centra seu posicionamento na concepção de que "o gênero seria algo individual, tomado ora como objeto de uma escolha consciente e deliberada do indivíduo, ora como um resultado causal de impressões do ambiente, no qual o indivíduo seria uma mera tela em branco" (MATTOS, 2018, p. 577).

Dessa maneira, é importante frisar que as intervenções pedagógicas nesse processo de construção das identidades de gênero possam superar tais certezas e oferecer aos alunos outras possibilidades de entendimentos consideradas não naturais. Daí se deriva a influência chamada de ideologia de gênero, havendo a necessidade da manutenção dessa naturalização biológica.

Portanto, para Mattos (2018):

Em resumo, os movimentos ultraconservadores têm se colocado tanto contra o gênero como "escolha individual" quanto contra "professores doutrinadores" que assujeitariam estudantes a desenvolver gêneros "não naturais". A combinação dessa dupla e contraditória acusação contra os estudos de gênero e sexualidades, condensada no truque da "ideologia de gênero", resulta em um emaranhado de afirmações que tem assombrado mães e pais, eleitoras/es, e promovido discursos de ódio contra qualquer debate que questione narrativas moralizantes (MATTOS, 2018, p. 578).

Nesse sentido, na visão dos movimentos ultraconservadores, as discussões e intervenções pedagógicas em sala de aula, a partir dos conhecimentos científicos produzidos sobre gênero e sexualidade, estariam sendo utilizadas como estratégia para os professores "doutrinarem" seus alunos e incitarem o desenvolvimento de gêneros tidos como "não naturais".

\section{O silenciamento do gênero e da sexualidade no PNE e na BNCC}

São documentos importantes para a efetivação de políticas democráticas e de ampliação ao acesso e permanência na educação formal, estabelecidas na Constituição Brasileira (BRASIL, 1988) e na LDB/EN, o PNE e a BNCC. O Plano Nacional de 
Educação-PNE é um documento no qual se definem diretrizes, metas e estratégias para a política educacional brasileira sendo rediscutido e reelaborado a cada decênio (atual PNE: 2014 a 2024) e Base Nacional Comum Curricular- BNCC é um documento referência para a construção dos currículos dos sistemas e redes de ensino de todo país.

Nesse sentido, destacamos como gênero e sexualidade estão contidos nesses documentos e quais debates foram travados para a inserção ou retirada, em sua redação final, visto que são bases para a criação de políticas educacionais no Brasil e para a reformulação de currículos escolares.

Em meio às discussões para a aprovação do Plano Nacional de Educação (2014), os slogans doutrinação e ideologia de gênero se fortaleciam diante dos grupos e mídias sociais, e seus agentes travaram intensas disputas durante a construção do Plano, culminando na retirada da obrigatoriedade das discussões sobre gênero e sexualidade no âmbito escolar do PNE, como destaca Miskolci (2018) e Balieiro (2018).

Nesse sentido, pode-se dizer que:

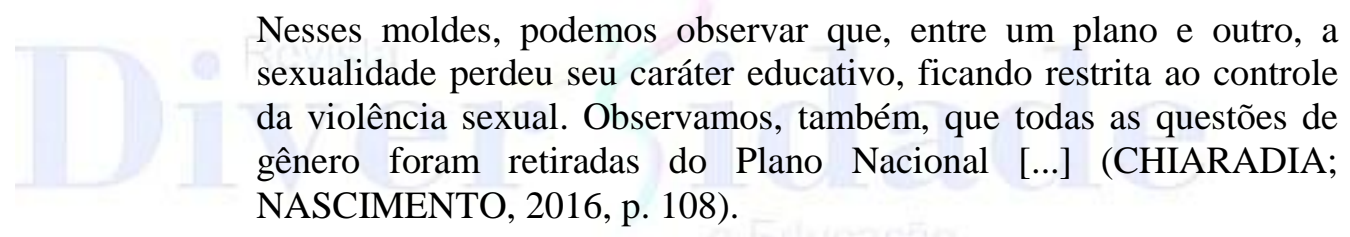

Sobre as questões de gênero e sexualidade no PNE (2014-2024), Chiaradia e Nascimento (2016) pontuam que a proposta envolvia tópicos tais como analisar os livros didáticos quanto ao conteúdo discriminatório acerca da mulher, do negro e das negras e dos povos indígenas, sendo também incluídas na formação docente as discussões relacionadas aos temas transversais e às questões de gênero. No entanto, por meio das muitas alterações realizadas, o conjunto de propostas presentes no PNE anterior (20012010) se reduziu a apenas uma estratégia no PNE atual, o combate a violência sexual.

Seffner (2016) destaca que o movimento que buscava a retirada das discussões sobre gênero e sexualidade, do Plano de Educação ficou conhecido como o movimento contra "ideologia de gênero", e suas ideias ganharam proporção em todo o país, de forma negativa, fazendo uma distorção também sobre as noções de sexualidade. Para esse autor,

[...] Grupos conservadores de variados matizes passaram a enxergar em qualquer abordagem de gênero a temível "ideologia de gênero", como se também não fosse ideologia o discurso que professam na condenação 
do gênero. Tal movimento iniciou com forte expressão em 2014 e atingiu seu ápice em 2015, sempre em sintonia com a elaboração e votação dos planos de educação (SEFFNER, 2016, p. 8).

Esse autor ainda ressalta que o movimento não propunha nenhuma inclusão explícita no PNE, “apenas a supressão dessa nomeação dos marcadores sociais da diferença, mais fortemente gênero e sexualidade, mas atingindo também raça, religião, geração" (SEFFNER, 2016, p. 8).

Dessa forma, é interessante notar que a retirada desses marcadores sociais, reafirma no processo educacional, a naturalização do que se entende por: ser homem e mulher, por se ter a família patriarcal como única e verdadeira, e por um único modo de viver o amor. A vida em sociedade, para esse movimento, acontece apenas por meio da reprodução biológica entre homem e mulher, na verdade,"biohomens e biomulheres, aqueles nascidos biologicamente homens e mulheres, e que desejam viver segundo a heteronormatividade" (SEFFNER, 2016, p. 8).

Para o debate de currículos, a BNCC começa a ser formulada no ano de 2015, após a aprovação do atual PNE. A primeira versão do documento foi disponibilizada para consulta pública entre setembro de 2015 e março de 2016. A segunda versão foi lançada no mês abril de 2016e a última versão foi lançada em abril de 2017 . No entanto, devido as discussões no legislativo sobre a proposta de reforma do Ensino Médio, as proposições para essa etapa da Educação Básica foram preteridas para 2018, separadas da Educação Infantil e do Ensino Fundamental.

Nessa perspectiva, Silva e Arantes (2017), destacam que a BNCC tem como base a necessidade de criação de currículos, servindo assim, como referencial para todas as escolas do Brasil, em todas as modalidades da Educação básica, sendo uma ferramenta que possibilita a formulação/reformulação do currículo que subsidia a proposta políticopedagógica das escolas.

No entanto, da primeira para última versão, muitas mudanças ocorreram, em particular, quando se fala de gênero e sexualidade. Alguns dos principais veículos de comunicação via-internet12 noticiaram essas mudanças ocorridas da segunda para a última

12 Disponível em: <https://www.brasil247.com/pt/247/brasil/289179/Mais-um-retrocesso-MECtira\%E2\%80\%98identidade-de-g\%C3\%AAnero\%E2\%80\%99\%E2\%80\%98orienta\%C3\%A7\%C3\%A3osexual\%E2\%80\%99-da-base-curricular.html>

Disponível em: <https://oglobo.globo.com/sociedade/educacao/cne-retira-genero-orientacao-sexual-dabase-curricular-22179063> 
versão da BNCC. Dessa maneira, já nos capítulos iniciais, mais precisamente na página 11, o texto da Base, na segunda versão, apresentava que:

A equidade requer que a instituição escolar seja deliberadamente aberta à pluralidade e à diversidade, e que a experiência escolar seja acessível, eficaz e agradável para todos, sem exceção, independentemente de aparência, etnia, religião, sexo, identidade de gênero, orientação sexual ou quaisquer outros atributos, garantindo que todos possam aprender (BRASIL, 2016, p.11).

No entanto, a versão final excluiu o termo "identidade de gênero" e "orientação sexual", como podemos fazer a leitura no documento oficial disponibilizado no site do Ministério da Educação para a BNCC:

A equidade requer que a instituição escolar seja deliberadamente aberta à pluralidade e à diversidade, e que a experiência escolar seja acessível, eficaz e agradável para todos, sem exceção, independentemente de aparência, etnia, religião, sexo ou quaisquer outros atributos, garantindo que todos possam aprender (BRASIL, 2017, p. 11).

Outras mudanças ocorreram nas páginas que citam as competências que devem ser trabalhadas no Ensino Fundamental, havendo também a exclusão de gênero e sexualidade, na unidade temática "Vida e evolução", no eixo sobre "Vida e sexualidade", previsto para o ensino de ciências do $8^{\circ}$ ano do ensino fundamental, nela retiraram das habilidades a serem desenvolvidas, mais duas expressões: "identidade de gênero" e “orientação sexual”. Dessa forma, a versão final ficou da seguinte maneira:“(EF08CI11) selecionar argumentos que evidenciem as múltiplas dimensões da sexualidade humana (biológica, sociocultural, afetiva e ética)" (BRASIL, 2017, p. 301).

Na mesma direção, os conteúdos de Ensino Religioso, na segunda versão da BNCC, definiam em um de seus eixos temáticos o estudo do "corpo, gênero e sexualidade nas tradições religiosas", no qual a escola deveria debater sobre as diferentes concepções de corpo, gênero e sexualidade para as religiões. Na última versão da documento, com a supressão, houve a substituição pelo eixo "princípios e valores éticos”13.

Disponível em:<www1.folha.uol.com.br/educacao/2017/04/1873366-ministerio-tira-identidade-degenero-e-orientacao-sexual-da-base-curricular.shtml>

13Disponível em: <http://basenacionalcomum.mec.gov.br/> 
A partir de Macedo (2017) podemos destacar que o movimento Escola Sem Partido há algum tempo vinha discutindo suas propostas para a BNCC, e os defensores dessas demandas ganharam espaço dentro do MEC e nas discussões acerca do texto final da Base nacional, a partir da entrada de Mendonça Filho (DEM), ministro da Educação no governo do Presidente Michel Temer (MDB).

Dentre as demandas da Escola Sem Partido para a BNCC, pode-se elencar algumas delas: Doutrinação produzida pelo currículo escolar, apoiado pelo MEC e pelos meios de comunicação, o ESP se posiciona contra o viés ideológico de esquerda que sustentaria o documento apresentado à consulta pública, a diversidade cultural nos currículos, contra a ideologia de gênero nos currículos escolares (MACEDO, 2017, p. 516).

A autora traz uma reflexão sobre esse conjunto de demandas conservadoras do Projeto Escola Sem Partido para a Base Nacional, na medida em que essas demandas são pontuais e promovem a exclusão explícita de demandas políticas de minorias sociais de raça, gênero e sexualidade, que mesmo de forma tímida vinham conseguindo espaço no currículo escolar ao longo dos anos.

Na visão de Paraíso (2016), o objetivo de interromper as poucas conquistas de grupos minoritários, principalmente de mulheres e LGBTs, ficam evidentes, precisamente no campo educacional, para atingir esse objetivo é imprescindível controlar o currículo, porém, esse é apenas um dos meios de controle que esse movimento ultraconservador deseja impor.

\section{Considerações Finais}

Voltando-se para aquilo que nesta pesquisa nos propusemos, destacamos que grupos ultraconservadores tem se utilizado de pânico moral para subverter os conceitos científicos atribuídos a gênero e sexualidade, propagando seus discursos conservadores no seio da sociedade, resultando na falácia da ideologia de gênero que tem sido utilizada como estratégia do Movimento Escola Sem Partido.

Entre inúmeros episódios que atestam o pânico moral criado sobre o tema, ressaltam-se as polêmicas criadas sobre o kit Escola Sem Homofobia e sobre a criação do Plano Nacional de Educação, que repercutiram negativamente na sociedade, prevalecendo distorções e visões religiosas sobre esse assunto. 
Os movimentos ultraconservadores, como o ESP, utilizam discursos falaciosos na tentativa de obstruir práticas de professores no que tange à temática de gênero e sexualidade, pretendendo assim, a proibição de qualquer discussão sobre o tema, demonstrando que esses grupos visam a manutenção daquilo que é tido como padrão na sociedade: a família patriarcal (pai, mãe e filhos), a heteronormatividade, a submissão feminina e seres humanos subjugados, sem consciência crítica.

Ao investigar a atualidade dos discursos sobre gênero e sexualidade, destaca-se o papel da igreja católica como instituição que combate os estudos de gênero, se contrapondo às conquistas de grupos considerados minorias sociais, como as mulheres e os LGBTs, em face da manutenção de seus valores. Para isso tem se organizado e difundido para vários países, ideias que subvertem debates e conquistas em torno de gênero e a sexualidade, estigmatizados como ideologia de gênero.

No Brasil, além das igrejas católicas e protestantes, outros grupos conservadores como o ESP, têm se valido daquilo que chamam de ideologia de gênero como ferramenta de censura às discussões de gênero e sexualidade nos espaços escolares. Tal movimento ganhou força com a proposição de projetos no legislativo, como os PLS 7180/2014, 867/2015, 1411/2015, 5487/2016 e, atualmente, com a retirada da obrigatoriedade da temática da Base Nacional Comum Curricular.

Portanto, fazem-se necessárias a reflexão e a produção de conhecimento sobre o tema, nas universidades e na sociedade, em geral, visando desconstruir e reconstruir o senso comum. Dessa maneira, é importante compartilhar e refletir acerca do que tem prevalecido nessas discussões em espaços de educação formal e não formal - escolas, movimentos sociais, centros comunitários, instituições públicas e privadas, entre outras, constituindo novos olhares e convivência na diversidade.

\section{Referências}

BALIEIRO, Fernando de Figueiredo. "Não se meta com meus filhos": a construção do pânico moral da criança sob ameaça. Cadernos pagu, Campinas, n. 53, 2018. Disponível em: http://dx.doi.org/10.1590/18094449201800530006. Acesso em: 01 mai. 2019.

BARREIRO, Alex et al. Ideologia de gênero? Notas para um debate de políticas e violências institucionais. Temáticas, Campinas, v. 24, n.47, p.223-246, fev/dez., 2016. 
BRASIL. Ministério da Educação. Base Nacional Comum Curricular: Proposta preliminar. Segunda versão revista. Brasília: MEC, 2016. Disponível em: http://basenacionalcomum.mec. gov.br/documentos/bncc-2versao.revista.pdf. Acesso em: 01 mai. 2019.

BRASIL. Ministério da Educação. Base Nacional Comum Curricular: Versão Final. Brasília: MEC, 2017. Disponível em: http://basenacionalcomum.mec.gov.br/wpcontent/uploads/2018/06/BNCC_EI_EF_1105 18_versaofinal_site.pdf. Acesso em março de 2020.

CARA, Daniel. O programa "escola sem partido" quer uma escola sem educação. In: Ação Educativa Assessoria, Pesquisa e Informação (Org).A ideologia do movimento Escola Sem Partido: 20 autores desmontam. — São Paulo: Ação Educativa, 2016. 168 p.

CHIARADIA, Cristiana de França; NASCIMENTO, Maria Lívia. A retirada da orientação sexual do currículo escolar: regulações da vida. sisyphusjournalofeducation,Lisboa, v. 5, n. 01, p.101-116, 2017.

CHIZZOTTI, Antonio. Pesquisa em ciências humanas e sociais. $5^{\circ}$ ed. São Paulo: Cortez, 2001. 208 p.

LOURO, Guacira Lopes. Gênero, sexualidade e educação: Uma perspectiva pósestruturalista. Petropolis, RJ: Vozes, 2007. 184 p.

LOURO, Guacira Lopes. O corpo educado: pedagogias da sexualidade. Guacira Lopes Louro (org.). $4^{\mathrm{o}}$ ed; $1^{\mathrm{a}}$ reim. Belo Horizonte: Autentica Editora, 2019. 224 p.

JUNQUEIRA, Rogério Diniz. "Ideologia de gênero": a gênese de uma categoria política reacionária - ou: a promoção dos direitos humanos se tornou uma "ameaça à família natural"? In: RIBEIRO, Paula Regina Costa, MAGALHÃES, Joana lira Corpes[org.] Debates contemporâneos sobre Educação para a sexualidade. Rio Grande: Ed. da FURG, 2017. 284 p.

MATTOS, Amanda Rocha. Discursos ultraconservadores e o truque da "ideologia de gênero": gênero e sexualidades em disputa na educação. Psicologia Política, São Paulo, v.18, n.43, set/dez. 2018. Disponível em: <http://pepsic.bvsalud.org/pdf/rpp/v18n43/v18n43a09.pdf>. Acesso em: 15 jun. 2019.

MACEDO, Elizabeth. As demandas conservadoras do movimento escola sem partido e a Base Nacional Curricular Comum. Educação \& Sociedade, Campinas, v. 38, n. 139, abril-junio. 2017. Disponível em: https://www.redalyc.org/articulo.oa?id=87351644014. Acesso em: 01 jul. 2018 
MIGUEL, Luis Felipe. "Doutrinação marxista" à "ideologia de gênero" - Escola Sem Partido e as leis da mordaça no parlamento brasileiro. Revista Direito e Práxis, Rio de Janeiro, v. 7, n. 15. 2016. Disponível em: https://www.epublicacoes.uerj.br/index.php/revistaceaju/article/view/25163/18213. Acesso em: 01. jul. 2018.

MINAYO, Marília Cecília de Souza (Org.). Pesquisa Social: teoria, método e criatividade. Petrópolis, RJ: Vozes, 2002. 112 p.

MISKOLCI, Richard. Exorcizando um fantasma: os interesses por trás do combate à “ideologia de gênero". Cadernos pagu, Campinas, n.53, 2018. Disponível em: http://dx.doi.org/10.1590/18094449201800530002. Acesso em: 01 mai. 2019.

PARAÍSO, Marlucy Alves. A ciranda do currículo com gênero, poder e resistência. Currículo sem Fronteiras, v. 16, n. 3,set./dez. 2016. Disponível em: www.curriculosemfronteiras.org. Acesso em: 01 de fevereiro de 2019.

PATERNOTTE, David; KUHAR, Roman. "Ideologia de gênero" em movimento. Psicologia Política, São Paulo, v.18, n.43, set/dez. 2018. Disponível em:

http://pepsic.bvsalud.org/pdf/rpp/v18n43/v18n43a05.pdf. Acesso em: 15 jun. 2019.

PENNA, Fernando Araujo. O ódio aos professores. In: Ação Educativa Assessoria, Pesquisa e Informação (Org.). A ideologia do movimento Escola Sem Partido: 20 autores desmontam o discurso. São Paulo: Ação Educativa, 2016a. 168 p.

PENNA, Fernando Araujo. Programa "Escola sem Partido": uma ameaça à educação emancipadora. In: GABRIEL, Carmem Teresa; MONTEIRO, Ana Maria; MARTINS, Marcus Leandro Bomfim (Org.). Narrativas do Rio de Janeiro nas aulas de história. 1. Ed. Rio de Janeiro: Mauad X, 2016b. 280 p.

SILVA, Maria José; ARANTES, Adlene Silva. Questões de gênero e orientação sexual no currículo, a partir da BNCC. In: CONGRESSO NACIONAL DE EDUCAÇÃO, 4, 2017. Anais... Paraíba: Editora Realize, 2017. S.p.

SCOTT, Joan. Gênero: uma categoria útil de análise histórica. Educação \& Realidade. Porto Alegre, v. 20, n. 2, p. 71-99, jul./dez., 1995.

SEFFNER, Fernando. Atravessamentos de gênero, sexualidade e educação: tempos difíceis e novas arenas políticas. In: REUNIÃO CIENTIFICA REGIONAL DA ANPED- UFPR, 11, 2016. Anais ...Curitiba: ANPED, 2016. p.1-17. 
SEVILLA, Gabriela; SEFFNER, Fernando. "Escola sem partido" e sem "ideologia de gênero": apontamentos sobre as mudanças na legislação educacional e suas implicações para o ensino de sociologia. In: SEMINÁRIO BRASILEIRO DE ESTUDOS CULTURAIS E EDUCAÇÃO/ SEMINÁRIO INTERNACIONAL DE EDUCAÇÃO,7, 2017. Anais... Canoas: PPGEDU, 2017. S.p.

SEVERINO, Antônio Joaquim. Metodologia do Trabalho Científico. $23^{\mathrm{a}}$ ed. São Paulo: Cortez, 2007. 304 p.

VENCATO, Ana Paula et al. A educação e o presente instável: repercussões da categoria "ideologia de gênero" na construção do respeito às diferenças Psicologia Política, São Paulo, v.18, n.43, set/dez. 2018. Disponível em:

http://pepsic.bvsalud.org/pdf/rpp/v18n43/v18n43a10.pdf. Acesso em: 15 jun. 2019.

Recebido em marco de 2020.

Aprovado em junho de 2020. 